\title{
BMJ Open 'You are just left to get on with it': qualitative study of patient and carer experiences of the transition to secondary progressive multiple sclerosis
}

\author{
F Davies, ${ }^{1}$ A Edwards, ${ }^{1} \mathrm{~K}$ Brain, ${ }^{1} \mathrm{M}$ Edwards, ${ }^{2} \mathrm{R}$ Jones, ${ }^{3} \mathrm{R}$ Wallbank, ${ }^{3}$ \\ N P Robertson, ${ }^{4}{ }^{F}$ Wood ${ }^{1}$
}

To cite: Davies F, Edwards A, Brain $\mathrm{K}$, et al. 'You are just left to get on with it': qualitative study of patient and carer experiences of the transition to secondary progressive multiple sclerosis. BMJ Open 2015;5: e007674. doi:10.1136/ bmjopen-2015-007674

- Prepublication history and additional material is available. To view please visit the journal (http://dx.doi.org/ 10.1136/bmjopen-2015007674).

Received 14 January 2015 Revised 21 May 2015 Accepted 22 May 2015

CrossMark

For numbered affiliations see end of article.

Correspondence to

Dr F Davies;

DaviesF9@cardiff.ac.uk

\section{ABSTRACT}

Objectives: Although the transition to secondary progressive multiple sclerosis (SPMS) is known to be a period of uncertainty for clinicians, who may find progressive disease challenging to objectively identify, little research has explored the experiences of patients and carers specifically during this transition period. Our objective was to explore what patients and their carers understand about their disease stage and describe their experiences and perspectives on the transition to SPMS.

Design: Semistructured qualitative interviews and subsequent validation focus groups were analysed using inductive thematic analysis.

Setting: South East Wales, UK.

Participants: 20 patients with MS and 13 carers were interviewed. Eight patients and two carers participated in focus groups.

Results: Four main themes around disease progression were identified. 'Realisation' describes how patients came to understand they had SPMS while 'reaction' describes their response to this realisation. The 'realities' of living with SPMS, including dealing with the healthcare system during this period, were described along with 'future challenges' envisaged by patients and carers.

Conclusions: Awareness that the transition to SPMS has occurred, and subsequent emotional reactions and coping strategies, varied widely between patients and their carers. The process of diagnosing the transition was often not transparent and some individuals wanted information to help them understand what the transition to SPMS meant for them.

\section{INTRODUCTION}

Multiple sclerosis (MS) is the most common disabling neurological condition affecting young adults. ${ }^{1}$ Most people with relapsing onset MS, which is the commonest form at diagnosis, will subsequently develop secondaryprogressive MS (SPMS) at some point in their disease. ${ }^{1}$ Relapsing MS is characterised by a

\section{Strengths and limitations of this study}

- The study describes the experience of transitioning to secondary progressive multiple sclerosis (SPMS) from the perspectives of people with MS and carers, which little previous research has focused on.

- Widely varying responses to this transition have been identified and explored.

- This study may help health professionals provide better support during the transition to SPMS by improving their understanding of how patients and carers experience this phase of the disease.

- All the participants live in one area so some of their experiences may be specific to their local context. Further research with people living in different areas and utilising different healthcare systems would be useful.

lack of disease progression during the periods between relapses. When the level of disability begins to increase independently of relapses, MS is termed secondary-progressive. ${ }^{2}$ Little is known about the healthcare experiences of people with MS (pwMS) at the onset of secondary progression, ${ }^{3}$ despite its vital importance as a milestone of future disability evolution, ${ }^{4}$ disease pathology and treatment options. ${ }^{5}$ Previous studies have examined specific support and information needs of pwMS at diagnosis and times of treatment selection, ${ }^{67}$ and have also explored general support needs of pwMS and their carers occurring throughout the disease course. ${ }^{8-11}$

Clinicians have described the patient's experience of receiving confirmation of the onset of SPMS as similar to 'being diagnosed again',(ref. 12, p.460) and also recognise the clinical challenge they face in objectively identifying transition to SPMS in individual patients. ${ }^{13}$ In part this is because of genuine diagnostic uncertainty as a result of the subtlety of signs of early progressive disease 
that on average lasts nearly 3 years. ${ }^{14}$ The lack of available evidence-based treatments for SPMS means that identification of disease progression may lead to the discontinuation of disease modifying agents. ${ }^{15}$ In turn, the frequency of neurology team contacts may decrease, potentially creating a feeling of abandonment ${ }^{16}$ at a time when pwMS are coming to terms with having a progressive disease, facing declining mobility and experiencing difficulties with maintaining normal work and social activities. ${ }^{17}$

In this study, we aimed to explore the experiences of pwMS of transition from relapsing onset MS to SPMS and to document views of carers during this period. We contend that transition to SPMS is likely to generate novel and specific support needs for both pwMS and their carers. We hoped to identify ways in which the provision of information and support could be improved to help professionals understand the specific needs of pwMS and carers at this stage and provide insights for those involved in service planning.

\section{METHODS}

Our research was funded by the MS Trust, with a view to increasing knowledge of patient and carer support needs around the transition to SPMS. A qualitative design was chosen as it was apparent that what was initially required was a deeper understanding of the issues from the perspectives of patients and carers. The methodology was based on social constructionism, which emphasises that the meaning and experience of illness is socially constructed, based on how individuals come to understand and live with their illness, and how illnesses are shaped by cultural and social factors. ${ }^{18}$

\section{Setting and recruitment}

The project was approved by South East Scotland Research Ethics Committee 01 (REC reference: 13/SS/ 0160). PwMS from three university health board areas in South Wales (Aneurin Bevan, Cardiff and Vale, and Cwm Taf) were identified using an extensive, wellvalidated clinical database held at the University Hospital of Wales, Cardiff, UK, which has been described previously. ${ }^{19}$ In all three areas all of the pwMS had access to a specialist MS nurse and could contact their MS team when required through a telephone helpline.

\section{Participant selection}

The inclusion criteria for pwMS were: (1) aged over 18 years, (2) diagnosed with MS with an Expanded Disability Status Scale (EDSS) score of between 4 and 8 recorded by a clinician in the previous year, (3) able to give informed consent, (4) does not have primary progressive MS. A purposive sampling strategy was used to identify pwMS close to the transition, and people with established SPMS who had recently experienced the transition. An MS specialist nurse (RJ) used the clinical information recorded on the database together with clinical judgement in advising which pwMS were most likely to be close to transition to SPMS, and also confirmed there were no known concerns or capacity issues relating to the invitation to participate. Seventy-four pwMS who met the inclusion criteria were sent postal invitations including written study information by the neurology team, aiming to recruit 20-30 participants. Carer participants were approached via the pwMS using snowball sampling techniques. When pwMS and carers returned expressions of interest forms by post the researcher (FD) made contact with the participants via telephone or email. Some carers were identified as being interested in participation and recruited opportunistically by the researcher while attending another prearranged interview. All participants provided written informed consent prior to participation.

\section{Data collection}

A semistructured interview guide using core questions with optional prompts was designed (see box 1). The guide was informed by existing literature from studies on: living with long-term conditions, health literacy and self-management as well as from discussion among the

Box 1 Interview guide summary (amendments for carer questions shown in brackets)

A. Current experience of multiple sclerosis (MS) How does your MS affect you (your friend/relative) day to day at the moment?

What do you find most bothersome?

(What do you think they find most bothersome? What do you find most bothersome?)

B. Sources of information and support

What support have you been offered to help you cope with your MS up to now (to help you cope with caring for someone with MS)?

What was the most useful thing about the support you were given?

How do you think support for patients (carers of people) with MS could be improved?

Where do you go to find information about how to manage MS?

Is there anything that you think stops people with MS (carers) from getting the support they need?

C. Changing support needs

What do you understand about the stage of MS that you are (your friend or relative is) at, at the moment?

If the person with MS (carer) specifically mentions transition or having secondary-progressive MS explore what finding this out meant to them and what sort of support they wanted at that time

As time has gone on, has the sort of support you have needed changed?

How would you like to receive support and information about MS?

Do you have any particular concerns about the future and how you will get the support you might need? 
authors and patient representatives. No substantial changes were made following the pilot interview with a patient representative, although minor changes to the wording of some questions were suggested. The interviews took place at the participants preferred locations. Data were reviewed after 17 patient interviews and 10 carer interviews had been conducted, at which point data saturation was evident and no new themes were emerging from newly collected data. ${ }^{20}$ Three additional patient interviews and three additional carer interviews were conducted to ensure that we had satisfied the requirement of data saturation at which point it was decided that interviewing could conclude. A standardised questionnaire was used to collect demographic information following the interviews. Questions on current walking ability (previously validated as an estimate of $\operatorname{EDSS}^{21}$ ) and perception of current MS disease stage were included. Date of diagnosis and most recent clinician EDSS score were obtained, with consent, from the patients' medical records.

\section{Respondent data validation}

Following initial analysis of the interview data, two focus groups were held to allow emerging concepts to be reported to participants for validation. ${ }^{22}$ Key issues raised during the patient and carer interviews were fed-back to the focus group participants. Using a group approach can help participants explore their views about norms of experience about a topic that might not be accessible in a one-to-one setting. ${ }^{23}$ The focus groups acted to validate the interview findings, to further refine the key themes and as an opportunity to explore new issues related to future service provision. All participants from the interview stage who had indicated interest in focus group attendance were invited.

\section{Analysis}

All interviews and focus groups were audio recorded and transcribed verbatim. An inductive thematic analysis of the interview transcripts was undertaken as described by Braun and Clarke. ${ }^{24}$ FD and FW independently read and made notes on four interview transcripts each. A codebook was generated through joint discussion and all transcripts were coded by FD using the software NVivo V.10 (QSR International). When new codes were generated inductively, the codebook was refined, and the refinements documented within the NVivo software as new topics emerged. Once all interview transcripts were coded FD began the process of identifying candidate themes which were then discussed with FW. The focus group data were coded using early candidate themes from the interview data and the themes were subsequently further refined. The full data set was then reviewed by FD to ensure the candidate themes were representative and the themes were named collaboratively (FD and FW). Again this process was logged in NVivo which served as an audit trail for our data analysis.

\section{RESULTS}

\section{Sample characteristics}

Participant characteristics are summarised in tables 1-3. Twenty-two pwMS expressed initial interest in the study (subsequently two withdrew: one due to health problems, one due to scheduling difficulties). Nine carers were identified by pwMS and interviews arranged. Four carers were identified by the researcher and recruited opportunistically. A total of 20 patients and 13 carers were interviewed by FD (an academic general practitioner (GP) with training in qualitative research). Eighteen pwMS and nine carers were interviewed individually. An additional two pwMS and four carers requested that their interviews were conducted jointly. Interviews were conducted at the participants' preferred locations, usually at their own home or the home of their relative $(\mathrm{N}=27)$. Three participants were interviewed on hospital premises to coincide with an appointment, two were interviewed at their workplaces and one participant was interviewed at a coffee shop.

Three pwMS and one carer attended the first focus group. Five pwMS and one carer attended the second

\begin{tabular}{|c|c|c|}
\hline Characteristics & $\begin{array}{l}\text { Patients } \\
\text { (total sample } \\
\text { size 20) }\end{array}$ & $\begin{array}{l}\text { Carers } \\
\text { (total sample } \\
\text { size } 14^{\star} \text { ) }\end{array}$ \\
\hline \multicolumn{3}{|l|}{ Sex } \\
\hline Female & 15 & 6 \\
\hline Male & 5 & 8 \\
\hline \multicolumn{3}{|l|}{ Age (years) } \\
\hline $31-40$ & 4 & 1 \\
\hline $41-50$ & 7 & 2 \\
\hline $51-60$ & 5 & 5 \\
\hline $61-70$ & 4 & 4 \\
\hline $71-80$ & 0 & 2 \\
\hline \multicolumn{3}{|l|}{ Level of education } \\
\hline No formal qualifications & 0 & 6 \\
\hline $\begin{array}{l}\text { Some qualifications up } \\
\text { to O-level or equivalent }\end{array}$ & 6 & 2 \\
\hline A-levels or equivalent & 2 & 2 \\
\hline $\begin{array}{l}\text { University level or } \\
\text { above }\end{array}$ & 12 & 4 \\
\hline \multicolumn{3}{|l|}{ Employment status } \\
\hline Employed FT & 2 & 2 \\
\hline Employed PT & 2 & 1 \\
\hline $\begin{array}{l}\text { Employed } \\
\text { (on long-term sick) }\end{array}$ & 1 & 0 \\
\hline $\begin{array}{l}\text { Unemployed-looking } \\
\text { for work }\end{array}$ & 1 & 1 \\
\hline $\begin{array}{l}\text { Out of the labour force } \\
\text { not seeking work }\end{array}$ & 9 & 2 \\
\hline Retired early & 2 & 2 \\
\hline Retired due to age & 3 & 5 \\
\hline Full-time carer & 0 & 1 \\
\hline
\end{tabular}


Table 2 MS duration, level of disability and current disease-modifying agent use of participants with MS

\begin{tabular}{|c|c|}
\hline $\begin{array}{l}\text { Time since MS } \\
\text { diagnosis (years) }\end{array}$ & $\begin{array}{l}\text { Patients, } \\
\text { n (total 20) }\end{array}$ \\
\hline $1-10$ & 7 \\
\hline $11-20$ & 10 \\
\hline$>21$ & 3 \\
\hline \multicolumn{2}{|c|}{ Patient estimated EDSS at interview } \\
\hline$<4$ & 1 \\
\hline 5 & 3 \\
\hline 5.5 & 1 \\
\hline 6 & 6 \\
\hline 6.5 & 4 \\
\hline 7 & 4 \\
\hline 7.5 & 1 \\
\hline \multicolumn{2}{|c|}{ Most recent clinician rated EDSS (within 1 year) } \\
\hline 4 & 2 \\
\hline 4.5 & 1 \\
\hline 5.5 & 1 \\
\hline 6 & 7 \\
\hline 6.5 & 8 \\
\hline 7.5 & 1 \\
\hline \multicolumn{2}{|c|}{ Currently receiving disease-modifying agent } \\
\hline Yes & 4 \\
\hline No & 16 \\
\hline
\end{tabular}

focus group (the one carer had not taken part in the interview phase). Both groups were held in a community meeting venue. FD led the focus groups and FW acted as assistant moderator-keeping notes of the discussion and ensuring that all topics had been appropriately covered. The semistructured interviews took between 27 and $75 \mathrm{~min}$. The focus groups lasted 79 and $88 \mathrm{~min}$, respectively. None of the participants were known to the researchers before study start.

\section{Key themes}

When discussing disease progression, four themes emerged: Realisation, Reaction, Reality and Recognising Future Challenges. The codebook and a table mapping the original codes to the key themes are provided in online supplementary appendix 1. Illustrative quotations for each theme are included in table 4. Although the

\begin{tabular}{ll} 
Table 3 & Carer relationship and duration of caring role \\
\hline Time as a carer (years) & Carers, $\mathbf{n}$ (total 14) \\
\hline $1-10$ & 8 \\
$11-20$ & 5 \\
$>21$ & 1 \\
Relationship to person with MS & \\
Spouse/partner & 8 \\
Parent & 4 \\
Sibling & 1 \\
Close friend & 1 \\
\hline MS, multiple sclerosis. &
\end{tabular}

data from pwMS and carers were initially explored independently, there was significant overlap between the data sets so a combined analysis was undertaken to derive the final themes. Issues which were more unique to each group were also evident and this is discussed where relevant.

\section{Realisation-finding out about the transition}

Some pwMS reported a gradual realisation of entering the secondary progressive phase. These people were often already aware that secondary progression could occur and started to identify their own increasing disability. In these situations discussion of the transition with professionals acted to confirm the suspicions of the pwMS. Although some pwMS were happy coming to a gradual realisation, others expressed frustration that the conversation was not initiated by their neurologist. In some cases, when health professionals brought up SPMS it was unexpected, while several participants only discovered the label by chance (such as through an overheard conversation or when sent a copy of the clinic letter written to their GP). When the news came as a surprise for pwMS, the confusion was heightened by a lack of understanding about how the diagnosis had been reached.

Preferences for when and how pwMS would have liked to have found out they had SPMS were closely linked to the significance they attributed to the label. PwMS and carers suggested that when SPMS was confirmed, pwMS needed an explanation of how SPMS was identified. They also wanted to know what having SPMS meant for them, what they should or could do for themselves and what the MS team could do to support them. Face-to-face discussion of the issue was generally preferred with written information seen as a useful adjunct. Some participants preferred to source information in their own time and recognised that early in the transition phase feelings of denial might be a barrier to absorbing information.

The 'realisation' theme was less evident in the carer data. Carers often found recognising a gradual deterioration in the person they cared for challenging. Carers usually relied heavily on the information that the pwMS gave them about their current stage.

\section{Reaction-what secondary progressive disease means}

The meaning attributed to transitioning to SPMS varied widely between pwMS. For some pwMS, SPMS was seen as just a label, which in itself had little relevance to the day-to-day reality of living with MS. Some pwMS were not interested in how clinicians chose to label their MS as whichever label was applied they believed their future prognosis remained difficult to accurately predict. Others were troubled by the fact that SPMS limited the treatment options available to them and that nothing could be done to influence subsequent progression. The discussion about reaching SPMS was often accompanied by the news that pwMS would no 
Table 4 Themes, components and illustrative quotations

\begin{tabular}{ll}
\hline Themes & Components \\
\hline Realisation & Method of finding out \\
& \\
& \\
Understanding of how \\
the diagnosis is made
\end{tabular}
Illustrative quotations

Reaction

Response to the news

The meaning of SPMS

Reality-living with progressive disease

\section{Symptoms}

Loss of independence

Limitations on social life

Change in identity

Supporting oneself

Support from others

Reality-

healthcare

experiences

around

transition
P016: The neurologist said to me, "You do realise you're secondary progressive," and I said "Yeah I've worked that one out" P010: When he [GP] was on the telephone to the clinic saying you know "got a patient whose been diagnosed with secondary", that's how I found out about it only hearing him on the phone. Nobody said to me you've got secondary progressive

P008: I knew over time because I couldn't walk as far as I used to, just slowed down a bit, so I knew it was sort of happening, yeah, so I was well aware of it really P044: I know there's no definitive, for anyone there's no specific test that they can do but yes it would be nice to know well okay why, or what do you determine or what do you look at in a person to then decide what MS they now have? P005: It's devastating, it's like you're grieving, you're grieving for what you've lost. P030: I first of all, I panicked. (INT: Did you?)

And I thought to myself "Oh my God, it's one of the worse ones", but it isn't, I know that now, cos I was bawling, I thought "Oh my God, I'm gonna die from it" P024: Natural part of the disease, I didn't have a negative thought upon it, I didn't sit down and cry or anything. Just take it as what it is, can't do anything else unfortunately

P023: It means that my chance of disease modifying therapy is limited

P006: Mobility was always a problem. It now is much more of a problem.

P020: Some days tiredness overwhelms me

C031: Some things that she'll say to me don't make sense, when she's talking I think "Why did you say that?"

P038: My wife has to prepare food for me, has to prepare drinks for me because I can't do it

P005: I can't get where I want to go and do what I want to do

C039: We don't go out as much as we'd like together.

P036: I don't go out anymore l'd rather stay in. Because the later you get in the day and then getting more sluggish, l'm hurting more and l've got constant pain in my eyes and I find I can't handle it and by 9 o'clock I'm in bed

P004: I do miss going to work because l've always worked and it's a bit strange not to go to work, and I do, I did find it hard to, well, to know what to do

P018: I would honestly love to have a different life so I could be there for my grandchildren

C045: We follow the press and the media and get the MS Society journals and everything. So for instance we will be following up the news that there might be a drug for secondary progressive sufferers available

P012: Twice a week I go to yoga with a lot of people who also have MS. And it's nice to speak and see all those people and they're very supportive and that sort of makes life a bit easier [....] it's some sort of support and you can ask other people for ideas about things and then sharing the information which helps. P013: I walk up and down the corridor for so many minutes and they watch that and then I don't understand what I'm meant to do with that when I go home P020: You know your appointment is quite limited so you are not there to have a counselling appointment are you? You are there to be told if you need medication or I don't know, I think, yes, I suppose in a way you are just left to get on with it in some ways

C028: We only tend to ring her [MS nurse] when it's important. We appreciate how busy she is and how understaffed they are but l'd say this; when she does come back to you, she gives you $100 \%$

P022: I think that when you are first diagnosed you get a lot of help, afterwards you just get left alone, nobody does anything and you have to keep going on and on saying I want this, I want this

C027: He [GP] (laughs) tells me that l've got to zip my mouth when I go in there if I go in there with him [son], I'm not allowed to say anything. I will, if I see him struggling to answer a question, I will, I will sort of, er ... (C028: Prompt him). C027:... prompt him or tell the doctor what is happening, but they don't like it 


\begin{tabular}{|c|c|c|}
\hline Themes & Components & Illustrative quotations \\
\hline $\begin{array}{l}\text { Recognising } \\
\text { future }\end{array}$ & Living with uncertainty & $\begin{array}{l}\text { C017: It's like living your life with a weight on your back all the time, we can't do, } \\
\text { we can't plan anything }\end{array}$ \\
\hline \multirow[t]{3}{*}{ challenges } & $\begin{array}{l}\text { Hoping for } \\
\text { maintenance }\end{array}$ & $\begin{array}{l}\text { P018: Well with the future I try not to think about it. I do think "Oh God, I just want } \\
\text { to be able to walk." }\end{array}$ \\
\hline & $\begin{array}{l}\text { Hoping for } \\
\text { improvement/cure }\end{array}$ & $\begin{array}{l}\text { P024: All I want is the MS cure, but when is that going to happen? I don't think it } \\
\text { would be in my lifetime }\end{array}$ \\
\hline & The carer relationship & $\begin{array}{l}\text { P002: You can't tell them [carers] everything and they often sit there and worry } \\
\text { and then don't like to start asking about things, just in case they upset us and... } \\
\text { P025: It's very difficult }\end{array}$ \\
\hline
\end{tabular}

longer be offered follow-up by a neurologist. This was interpreted by some as disinterest from the medical profession and led to a sense of abandonment as it appeared care had been 'down-graded'. Some pwMS described with frustration that they felt professional support and information provision was more focused on the earlier stages of the disease. In others, the confirmation of SPMS triggered a significant emotional reaction; concerns that deterioration might be imminent and periods of denial were described. Transitioning to SPMS could prompt the final realisation that things were not going to improve, which could trigger feelings of loss around their former status and future plans. PwMS described that during the earlier phases of the disease they were still able to get on with life as normal during periods of remission, but when progression occurred the pervasive effects of MS could no longer be ignored. While many described a profound and negative emotional reaction to the life changes occurring during the transition, others described reaching SPMS as further motivation to try to fight the disease and maintain some level of control.

Similar to the realisation theme, the reaction theme was represented less within the carer data. Some carers explained what they perceived the impact to have been on the pwMS, but for the carers themselves the label of SPMS often had little personal significance.

\section{Reality-living with progressive disease}

PwMS and carers described multiple physical and cognitive symptoms of MS. Declining mobility had a major impact on daily life, restricting independence. The more invisible symptoms including fatigue, pain, low mood, cognitive problems and personality changes were even more difficult for some to cope with. Although cognitive issues were recognised by the pwMS they were often particularly challenging for the carers to deal with. Carers were sometimes unsure whether symptoms could definitely be attributed to MS and could find the subtle cognitive changes in pwMS confusing. Many participants recognised that it was the knock-on effect that one symptom could have on others, for example, fatigue impacting on mobility and cognition, together with symptom unpredictability and individual variability that made MS particularly difficult to manage.

Simple daily activities had become difficult for some and in general carers described taking on an increased number of domestic chores. Disease progression often meant pwMS could no longer partake in the activities that had previously defined their identity, in the workplace and socially. This frequently led to a re-evaluation of personal identity. Leaving the workplace, described by one person with MS as 'like losing your arm' (P022) appeared particularly difficult for those who placed great importance on working. Others described the inability to fulfil family and household roles difficult to accept. Both pwMS and carers recognised how their social lives had become limited. Some recognised that accepting that they needed assistance could make their lives easier and had adapted to their changing disability by modifying activities or taking up new enjoyable roles. Keeping active physically and socially was important to most pwMS, who were highly motivated to do what they could. Keeping informed about MS also appeared to help some pwMS and carers to feel they were doing something active to support themselves. PwMS and carers described the role of their families and friends, employers, peer support and wider societal attitudes in helping them to deal with the reality of disease progression.

\section{Reality - healthcare experiences around transition}

Many participants could not understand the infrequency of planned healthcare contacts in view of the significant impact MS had on their lives. Many felt a lack of funding limited service provision and worried about future funding cuts. There was frustration that the health and social care systems did not always actively promote the services available and that it was necessary to be 'pushy'.

Expectations of appointments with the MS team varied, from simply having someone to talk to, to getting a 'progress report' on their MS and treatment information. PwMS often felt time pressured within their appointments and those who were frustrated with their healthcare experiences found services were not tailored 
to their own information needs and preferences. PwMS described how sometimes they felt appointments were too focused on addressing the agenda of the professional they saw (eg, to carry out physical examinations and update their records). In these circumstances, pwMS struggled to understand what they were supposed to gain from attendance. Some pwMS took lists to their appointments to ensure their own agenda was addressed.

Continuity of care helped patients to feel well supported. Confidence in their healthcare professionals evolved over time as positive past experiences reassured pwMS and carers that the healthcare system would provide any future support they might need. Although GPs could provide continuity, many did not expect their GP to be an expert in MS and preferred to utilise specialist teams. A few participants raised concerns about 'bothering' healthcare professionals, often taking steps to try to support themselves before seeking help. Carers often attended review appointments, some seeing this as a useful opportunity to have their own questions answered while others attended primarily to support to the pwMS. Many carers felt they had useful information they could provide during appointments and wanted to feel that their contribution was valued although this was often not their experience. In general carers were less likely to use health professionals as part of their own support network. They valued the health professionals for how they could support the pwMS, and often if the pwMS were adequately supported this had a positive impact on carers. Carers had rarely been offered support for themselves and several commented on the fact the research interview was their first ever opportunity to formally discuss their caring responsibilities.

\section{Recognising future challenges-hopes for the future}

Different strategies were used by pwMS and carers in dealing with the uncertainty associated with the progression of MS. Some avoided thinking about the future describing it as futile, given the unpredictable clinical course of MS. However, the burden of trying to live with this unpredictability was recognised. Some participants were able to reflect on the ways in which they had successfully overcome challenges in the past to gain confidence in their ability to do the same in the future. Deterioration in their own condition was the main concern described by pwMS, whereas carers worried about how the person with MS would cope with declining function and how they would cope themselves. Some pwMS and carers expressed discomfort in the evolution of the role of the carer, while others saw caring as a duty they were obliged and happy to take on. The difficulties of discussing MS between pwMS and carers were recognised with both parties fearing causing upset. Participants recognised that neither the person with MS nor the carer really had a full understanding of how the situation was impacting on the other, compounded by a lack of communication. Carers were keen that in the face of increasing disability they did what they could to maintain what independence was possible for the pwMS. However, some felt conflicted about balancing this desire with trying to protect the person, also expressing concerns about being overprotective. Many pwMS hoped to be able to maintain their current level of function; some hoped to benefit from a future cure while others described this as a more distant aspiration.

\section{DISCUSSION}

Our participants with MS came to know that they had SPMS in a variety of ways, from gradual personal realisation to a medical decision the basis of which was hard to understand. Some pwMS learned they had SPMS without any advanced knowledge or understanding of what SPMS meant for them which sometimes caused confusion and upset. In other cases the medical labelling of the transition seemed to occur after the patient had already accepted disease progression and so was of little consequence. PwMS and carers described the reality of living with MS on a daily basis with its associated physical, social and psychological impact. Efforts were made to maintain hope while facing an uncertain future.

The current study examines a stage of the disease recognised by clinicians as being challenging for professionals and patients alike, and provides evidence of the experience of transitioning to SPMS for pwMS and carers, which to date has not been well described. The participants were varied in terms of age and duration of experience with MS. Varied experiences of the transition itself have been identified and described. The professional background of our research team, which included specialist MS health professionals, academic GPs and social scientists has helped to ensure that any particular professional biases that may have emerged throughout the analysis have been discussed and challenged during data analysis discussions. The participants all lived in one geographical area so some of their experiences may relate to the organisation of the local healthcare system. Many participants were older and out of the work force (and so more likely to have available time to participate in research) and although some were younger and in work, the challenges for this group may not have been fully explored. The carer group tended to be older, including some parent carers, perhaps reflecting that younger carers who may be working full time may not identify with the carer label. We also recognise that carers were not well represented in the focus groups. As the regional clinical database employed by the specialist team does not record 'in transition' as a disease stage it was difficult to identify patients most suitable for inclusion, and some of the participants felt they had transitioned some years ago. Consequently for those people we were relying on retrospective accounts which may have been influenced by subsequent experiences.

The experience of living with MS described by patients in this study is well understood and previously 
similarly described. Living with uncertainty, and experiencing denial and a sense of loss of identity are known to be important challenges experienced by many, while some also describe being able to reach acceptance and maintain hope. ${ }^{17}{ }^{25-29}$ We believe this study highlights that, for some, the transition to SPMS may be a particular 'fear-point' (ref. 30, p.18) in the disease course, triggering a significant emotional reaction and generating a need for additional support.

Those patients with more positive experiences of the realisation and reaction phases tended to be those with the knowledge required to interpret the transition to SPMS for themselves. Anticipatory preparation can facilitate patients' personal transitions, but in order to prepare patients require knowledge about what to expect and what strategies they might find helpful. ${ }^{31}$ Patients cannot engage with the process of a transition, by for example seeking out information and proactively modifying activities, if they do not recognise a transition is occurring. ${ }^{31}$ PwMS have expressed a desire for two-way communication with their health professionals and wish to feel they are working in partnership together. ${ }^{30}{ }^{32}$ Previous research showed that pwMS did not want information to be 'sugar-coated's0 and felt betrayed or patronised if they believed clinicians had chosen to withhold information. Too much information was generally seen as better than not enough. ${ }^{30}$ Although knowledge has been noted to have an important role in decreasing fear in $\mathrm{MS}^{27}$ gaps have been identified, here and elsewhere between the level of information patients desire and the amount professionals actually provide. ${ }^{10} 33$

Like those oncology patients also experiencing a transition in their condition and care ${ }^{34}$ some of our participants, described feeling abandoned and unclear about future options. Clinicians may try to spare their patients from diagnostic uncertainty and uncomfortable knowledge $^{35}$ and feel reluctant to reveal difficult diagnoses and prognoses. ${ }^{36}{ }^{37}$ This may partly explain why so few of our participants described transition discussions as being initiated by their neurologist. Clinicians tend to be reluctant to disclose an upsetting diagnosis that has little benefit for the patient ${ }^{37}$ though they are more likely to consider formalising the diagnosis if they perceive potential gain. ${ }^{38}$ Doctors who are uncomfortable with discussing transitions may use ambiguous language, provide incomplete information and minimise the significance of results. ${ }^{39}$ Communication skills training for clinicians discussing these transitions of care has previously proven beneficial, ${ }^{40}{ }^{41}$ and the introduction of similar training for neurologists has been suggested. ${ }^{42}$ This could facilitate an exchange of relevant information and potentially avoid situations we have described where pwMS feel neurologists are not interested in SPMS, and see SPMS is a 'demotion' in the potential future outcome and the quality of expected care. Clearer communication, around the rationale for nurse-led follow-up in particular, might help alleviate the concerns some participants expressed about no longer being reviewed by a neurologist.

Being confronted with disease progression prompted significant emotional reactions among some of our participants. PwMS are keen to see improvements in the availability of psychological support, which they recognised as an important deficit in available services. ${ }^{11} 1217$ Participants described employing differing coping strategies during the transition phase. A chosen coping strategy may be helpful or unhelpful depending on the situation. ${ }^{43}$ Although denial and unrealistic optimism may initially help people to deal with the stress of their changing circumstances, in the long term, failure to acknowledge emotions may leave them unresolved. ${ }^{45} 46$ Emotions need to be expressed and processed over time in order to facilitate adjustment ${ }^{44}$ which may require social and professional support. Soundy et $a l^{28}$ described how people who had reached acceptance of their MS diagnosis and prognosis expressed hope through being positive, accessing support and taking each day as it comes. Our participants described utilising selfmanagement strategies, and participation in selfmanagement is known to promote good adjustment. ${ }^{44}$ Health professionals can capitalise on this interest in self-management by facilitating access to appropriate information and engagement in physical and social activity.

The stages that carers may pass through in their acceptance of support have been described as rejecting, resisting, seeking and accepting support. ${ }^{46}$ Most carers in our study appeared to be in the first two stages and many seemed able to cope independently. The lack of previous discussion with professionals around their own well-being suggested that until carers are carrying out the physical tasks of caring, their own support needs can be easily overlooked, compounded by the fact that carers themselves may reject support.

Further research that defines objective markers of the transition to SPMS would be extremely useful for clinicians and their patients. The current tendency not to confirm SPMS until it is certain may make identifying patients at the transition stage for future research challenging. Observation of clinical encounters may be useful to confirm objectively what occurs when the transition is discussed and to identify areas for improvement.

\section{CONCLUSION}

Awareness that the transition to SPMS is occurring or has occurred, and subsequent emotional reactions and coping strategies, vary widely between pwMS and their carers. PwMS and carers want to know what SPMS means for them and what they could be doing to help themselves. If health professionals can provide these explanations, pwMS may feel empowered to self-manage while feeling confident that health professionals will form part of a supportive network for the future. 
Author affiliations

${ }^{1}$ Institute of Primary Care and Public Health, Cardiff University, Cardiff, UK

${ }^{2}$ School of Human Sciences, Swansea University, Swansea, UK

${ }^{3}$ Department of Neurology, University Hospital of Wales, Cardiff, UK

${ }^{4}$ Institute of Psychological Medicine and Clinical Neurosciences, Cardiff

University, Cardiff, UK

Acknowledgements The research team acknowledge the support of the MS Trust and the National Institute for Health Research, through the Comprehensive Clinical Research Network. The authors would like to thank al of the interview and focus group participants for sharing their experiences. The authors are also grateful for the support and suggestions of Tracy Nicholson, Rebecca Pearce, Gayle Sheppard and Barbara Stensland who were members of the study advisory group.

Contributors FD conducted the interviews and focus groups, took a lead role in the data analysis and drafted the manuscript. AE developed the research protocol, oversaw conduct and analysis of the research data, and contributed to drafting of the manuscript. KB, ME, RJ, RW and NPR contributed to the development of the research protocol, advised on the conduct of the research, and reviewed and contributed to drafts of the paper. RJ also identified suitable participants. FW contributed to the development of the research protocol, advised on and assisted with data collection, provided advice on data analysis and coanalysed a sample of transcripts and contributed to the drafting of the manuscript.

Funding This work was supported by the MS Trust [grant number 505859]. Competing interests None declared.

Ethics approval South East Scotland Research Ethics Committee 01.

Provenance and peer review Not commissioned; externally peer reviewed.

Data sharing statement No additional data are available.

Open Access This is an Open Access article distributed in accordance with the Creative Commons Attribution Non Commercial (CC BY-NC 4.0) license, which permits others to distribute, remix, adapt, build upon this work noncommercially, and license their derivative works on different terms, provided the original work is properly cited and the use is non-commercial. See: http:// creativecommons.org/licenses/by-nc/4.0/

\section{REFERENCES}

1. Murray TJ. Diagnosis and treatment of multiple sclerosis. $B M J$ 2006;332:525-7.

2. Lublin FD, Reingold SC. Defining the clinical course of multiple sclerosis: results of an international survey. National Multiple Sclerosis Society (USA) Advisory Committee on Clinical Trials of New Agents in Multiple Sclerosis. Neurology 1996;46:907-11.

3. Methley A, Chew-Graham C, Campbell S, et al. Experiences of UK health-care services for people with Multiple Sclerosis: a systematic narrative review. Health Expect 2014. [epub ahead of print] doi:10.1111/hex.12228

4. Vukusic S, Confavreux C. Natural history of multiple sclerosis: risk factors and prognostic indicators. Curr Opin Neurol 2007;20:269-74.

5. Dutta R, Trapp BD. Pathogenesis of axonal and neuronal damage in multiple sclerosis. Neurology 2007;68(22 Suppl 3):S22-31; discussion S43-54

6. Solari A. Effective communication at the point of multiple sclerosis diagnosis. Mult Scler 2014;20:397-402.

7. Heesen C, Solari A, Giordano A, et al. Decisions on multiple sclerosis immunotherapy: new treatment complexities urge patient engagement. J Neurol Sci 2011;306:192-7.

8. Forbes A, While A, Taylor M. What people with multiple sclerosis perceive to be important to meeting their needs. J Adv Nurs 2007;58:11-22.

9. Koopman WJ, Benbow CL, Vandervoort M. Top 10 needs of people with multiple sclerosis and their significant others. J Neurosci Nurs 2006;38:369-73.

10. Lorefice L, Mura G, Coni G, et al. What do multiple sclerosis patients and their caregivers perceive as unmet needs? BMC Neurol 2013;13:177.

11. Ytterberg $\mathrm{C}$, Johansson $\mathrm{S}$, Gottberg $\mathrm{K}$, et al. Perceived needs and satisfaction with care in people with multiple sclerosis: a two-year prospective study. BMC Neurol 2008;8:36.
12. Deibel F, Edwards M, Edwards A. Patients', carers' and providers' experiences and requirements for support in self-management of multiple sclerosis: a qualitative study. Eur J Person Centered Healthc 2013;1:457-67.

13. Palavra $\mathrm{F}$, Tur $\mathrm{C}$, Tintore $\mathrm{M}$, et al. Secondary progression is not the only explanation. Acta Med Port 2014;27:393-6.

14. Sand IK, Krieger S, Farrell C, et al. Diagnostic uncertainty during the transition to secondary progressive multiple sclerosis. Mult Scler 2014;20:1654-7.

15. Association of British Neurologists. Revised (2009) Guidelines for Prescribing in Multiple Sclerosis 2009 [7/10/14]. http://www.mstrust. org.uk/competencies/downloads/abn_ms_guidelines_2009_final.pdf

16. Johnson J. On receiving the diagnosis of multiple sclerosis: managing the transition. Mult Scler 2003;9:82-8.

17. Malcomson KS, Lowe-Strong AS, Dunwoody L. What can we learn from the personal insights of individuals living and coping with multiple sclerosis? Disabil Rehabil 2008;30:662-74.

18. Conrad P, Barker KK. The social construction of illness key insights and policy implications. $J$ Health Soc Behav 2010;51(Suppl 1): S67-79.

19. Moore $\mathrm{P}$, Harding $\mathrm{KE}$, Clarkson $\mathrm{H}$, et al. Demographic and clinical factors associated with changes in employment in multiple sclerosis. Mult Scler 2013;19:1647-54

20. Pope C, Ziebland S, Mays N. Analysing qualitative data. In: Pope C, Mays N, eds. Qualitative research in health care. London: BMJ Books, 2000:135-48.

21. Ingram G, Colley E, Ben-Shlomo $\mathrm{Y}$, et al. Validity of patient-derived disability and clinical data in multiple sclerosis. Mult Scler 2010;16:472-9.

22. Punch KF. Introduction to research methods in education. London: Sage Publications, 2009.

23. Kitzinger J. Qualitative research. Introducing focus groups. BMJ 1995;311:299-302.

24. Braun V, Clarke V. Using thematic analysis in psychology. Qual Res Psychol 2006;3:77-101.

25. Irvine H, Davidson C, Hoy K, et al. Psychosocial adjustment to multiple sclerosis: exploration of identity redefinition. Disabil Rehabil 2009;31:599-606.

26. Miller $\mathrm{CM}$. The lived experience of relapsing multiple sclerosis: a phenomenological study. J Neurosci Nurs 1997;29:294-304.

27. Kirkpatrick Pinson DM, Ottens AJ, Fisher TA. Women coping successfully with multiple sclerosis and the precursors of change. Qual Health Res 2009;19:181-93.

28. Soundy A, Benson J, Dawes $\mathrm{H}$, et al. Understanding hope in patients with Multiple Sclerosis. Physiotherapy 2012;98:344-50.

29. Wilkinson HR, das Nair R. The psychological impact of the unpredictability of multiple sclerosis: a qualitative literature meta-synthesis. Br J Neurosci Nurs 2013:9:172-8.

30. Thorne S, Con A, McGuinness L, et al. Health care communication issues in multiple sclerosis: an interpretive description. Qual Health Res 2004;14:5-22.

31. Meleis Al, Sawyer LM, Im E, et al. Transition Theory. In: Meleis Al, ed. Transitions theory: middle-range and situation specific theories in nursing research and practice. New York: Springer Publishing Company, 2010:52-83.

32. Ploughman M, Austin MW, Murdoch M, et al. The path to self-management: a qualitative study involving older people with multiple sclerosis. Physiother Can 2012;64:6-17.

33. Edmonds P, Vivat B, Burman R, et al. 'Fighting for everything': service experiences of people severely affected by multiple sclerosis. Mult Scler 2007:13:660-7.

34. Gardiner $\mathrm{C}$, Ingleton $\mathrm{C}$, Gott $\mathrm{M}$, et al. Exploring the transition from curative care to palliative care: a systematic review of the literature. BMJ Support Palliat Care 2011:1:56-63.

35. Storstein A. Communication and neurology--bad news and how to break them. Acta Neurol Scand Suppl 2011(191):5-11.

36. Mitchell AJ. Reluctance to disclose difficult diagnoses: a narrative review comparing communication by psychiatrists and oncologists. Support Care Cancer 2007:15:819-28.

37. Kaduszkiewicz $\mathrm{H}$, Bachmann $\mathrm{C}$, van den Bussche $\mathrm{H}$. Telling "the truth" in dementia--do attitude and approach of general practitioners and specialists differ? Patient Educ Couns 2008;70:220-6.

38. Hansen EC, Hughes C, Routley G, et al. General practitioners experiences and understandings of diagnosing dementia: factors impacting on early diagnosis. Soc Sci Med 2008;67: 1776-83.

39. Fallowfield LJ, Jenkins VA, Beveridge HA. Truth may hurt but deceit hurts more: communication in palliative care. Palliat Med 2002;16: 297-303.

40. Grainger MN, Hegarty S, Schofield P, et al. Discussing the transition to palliative care: evaluation of a brief communication 
skills training program for oncology clinicians. Palliat Support Care 2010;8:441-7.

41. Goelz T, Wuensch A, Stubenrauch S, et al. Specific training program improves oncologists' palliative care communication skills in a randomized controlled trial. J Clin Oncol 2011;29:3402-7.

42. Holloway RG, Gramling R, Kelly AG. Estimating and communicating prognosis in advanced neurologic disease. Neurology 2013;80:764-72.

43. Folkman S, Moskowitz JT. Coping: pitfalls and promise. Annu Rev Psychol 2004:55:745-74.
44. de Ridder D, Geenen R, Kuijer R, et al. Psychological adjustment to chronic disease. Lancet 2008;372:246-55.

45. Fournier M, Ridder D, Bensing J. Optimism and adaptation to chronic disease: the role of optimism in relation to self-care options of type 1 diabetes mellitus, rheumatoid arthritis and multiple sclerosis. Br J Health Psychol 2002;7:409-32.

46. McKeown LP, Porter-Armstrong AP, Baxter GD. Caregivers of people with multiple sclerosis: experiences of support. Mult Scler 2004;10:219-30. 